\title{
Behavior of Two Foundry Cobalt-Based Alloys Exposed to a Hot Complex Gaseous Mixture Simulating the Atmosphere in a Waste- to-Energy Boiler. Part 1: Case of the Alloy Exposed to the Complex Gas Stream
}

\author{
Lionel Aranda ${ }^{1}$, Thierry Schweitzer ${ }^{1}$, Patrice Berthod ${ }^{1,{ }^{*}}$, Christophe Rapin ${ }^{1}$, Didier \\ Souchon $^{2}$, Farès Maad ${ }^{2}$ and Jean-Michel Brossard ${ }^{2}$ \\ ${ }^{1}$ Institut Jean Lamour (UMR 7198), University of Lorraine, Campus ARTEM, 2 allée André Guinier 54000 \\ Nancy, France \\ ${ }^{2}$ Veolia Environnement Recherche et Innovation, Zone Portuaire, 291 Avenue Dreyfous Ducas, 78520 Limay, \\ France
}

\begin{abstract}
: he refractory materials required for waste-to-energy boilers endure severe working conditions, such as exposure to heat and hot oxidation / corrosion. Thanks to their high temperature properties cobalt-based alloys may respond to these properties requirements. In this work two model alloys based on cobalt and rich in chromium were elaborated by casting and samples were prepared by cutting and polishing. These samples were exposed, one to a hot complex gaseous mixture particularly aggressive reproducing the atmosphere in WtE boilers in service (presence of water vapor, di-oxygen, carbon di-oxide, hydrogen chloride), and the other to synthetic ashes, both for more than two hundreds hours. After test the samples were characterized by X-ray diffraction and SEM observations. On sample exposed to the complex gas stream a $\{10$ to $15 \mu \mathrm{m}\}$-thick oxide scale formed on the surface of the sample exposed to the gas mixture. It involved all the elements of the alloy and it obviously developed both inwards and outwards as suggested by the position of the oxidized carbides.
\end{abstract}

Keywords: Cobalt-chromium alloys, $\mathrm{HCl}$ gas, $\mathrm{CO}_{2}$, Water vapour, Hot corrosion.

\section{INTRODUCTION}

The waste-to-energy boilers are, in service, exposed to fireside corrosion [1]. These metallic parts stay in a very aggressive environment where gases such as $\mathrm{SO}_{2}, \mathrm{SO}_{3}$ and $\mathrm{HCl}$ are present [2], as well as the ashes formed [3, 4]. Corrosion-resistant materials or coatings to protect them must be used to allow lifetimes great enough [5]. For instance refractory alloys based on iron and nickel and rich enough in chromium [6] may be suitable for this application while coatings may be envisaged for a better behaviour [7]. Refractoriness high enough and resistance against hot corrosion may be also brought by cobalt-based superalloys. Indeed most of them present high melting points [8] and contain 25 to more than 30 wt.\% of chromium [9]. This allow them to be used for long lifetimes in severe conditions mixing mechanical solicitations, hot corrosion by melts and hot oxidation by air or burner gases [10].

The subject of the present study is to test two model alloys belonging to this category, a one strengthened by chromium carbides and another one reinforced by

*Address correspondence to this author at the Institut Jean Lamour (UMR 7198), University of Lorraine, Campus ARTEM, 2 allée André Guinier 54000 Nancy, France ; Tel: +33-372 7427 29;

E-mail: patrice.berthod@univ-lorraine.fr tantalum carbides, in an experimental apparatus reproducing the working conditions of WtE boilers. This aims to estimate the potential interest of chromiaforming cobalt-based superalloys for this type of application for which iron-based or nickel-based alloys are generally employed. In this first part this is the case of the sample exposed to the complex gas stream which will be studied.

\section{MATERIALS AND METHODS}

\section{Origin of the Alloy Used in This Study}

A sample coming from ingots especially elaborated by foundry in the frame of an earlier study, which was still available, was used for this work. This alloy, called "TAC", is rather complex. Its chemical composition contains cobalt as base element (bal.), $10 \mathrm{wt} . \% \mathrm{Ni}$ for stabilizing the austenitic structure of the matrix, 30 wt.\% $\mathrm{Cr}$ for favouring a chromia-forming behaviour to correctly resist both oxidation and corrosion, $0.5 \mathrm{wt} . \% \mathrm{C}$ for promoting the formation of interdendritic carbides, and $7.5 \mathrm{wt} . \%$ of tantalum for obtaining $\mathrm{TaC}$ carbides as single carbides present. This composition, successfully obtained in the alloy, led to the wished microstructure: dendritic matrix of a solid solution of cobalt with nickel and chromium atoms in substitution and carbon in insertion, and eutectic script-like tantalum carbides in the interdendritic spaces. 


\section{The Experimental Apparatus Used}

The apparatus with which the tests were carried out is presented in Figure 1. The conditions of a WtE boiler in service were reproduced, thanks to a gas burner allowing the generation of a hot mixture gas of interest $\left(\mathrm{H}_{2} \mathrm{O}, \mathrm{CO}_{2}\right)$ with introduction of industrial scoria in the produced combustion gases. The ashes were introduced by a screw feeder. Pure $\mathrm{SO}_{2}$ came from a bottle in which it was present as a compressed gas and $\mathrm{HCl}$ was introduced as an aqueous solution which was injected using a metering pump. The generated smokes were washed by a water shower. Scoria was recovered using a decanter. The "TAC" sample, which was suspended, was exposed to the gas mixture (1100 ppm of $\mathrm{HCl}, 18 \%$.vol $\mathrm{H}_{2} \mathrm{O}, 8 \%$.vol $\mathrm{O}_{2}$ and $5 \%$.vol $\mathrm{CO}_{2}$ ). It was exposed at $550 \pm 10^{\circ} \mathrm{C}$ during 260 hours in these conditions.

\section{Characterization of the Samples After Tests}

Prior to metallographic preparation the tested sample was subjected to X-ray diffraction (XRD). It was thereafter embedded in a cold resin mixture and cut. It was then ground using $\mathrm{SiC}$ papers with grades varying from 240 to 2400 . Water was avoided as lubricant to do not damage the corrosion products. Kerdane (dearomatized petrol, cleaning and degreasing) was used instead. Textile disk enriched with $1 \mu \mathrm{m}$ diamond particles were used for the following polishing step (lubricant: absolute ethanol). Examinations were carried out using a JEOL JSM6010LA Scanning Electrons Microscope (SEM) and to Energy Dispersive Spectrometry (EDS) measurements. Two modes were used: Secondary Electrons (SE) and Back Scattered Electrons (BSE).

\section{RESULTS}

Some SEM micrographs of the surface of the "TAC" sample are given in Figure 2. They are taken in the SE imaging mode, at two different magnifications. The observed corrosion products are composed of oxides

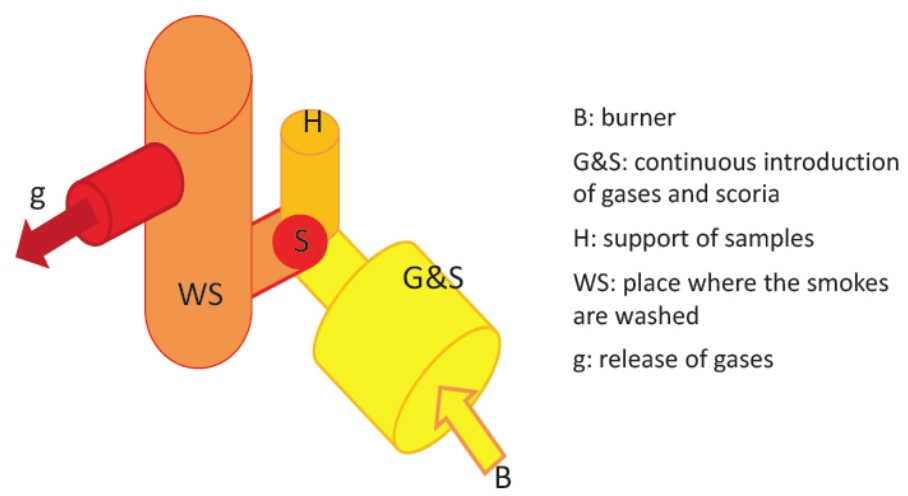

Figure 1: Scheme of the apparatus used for reproducing the conditions known by WtE boilers in service.
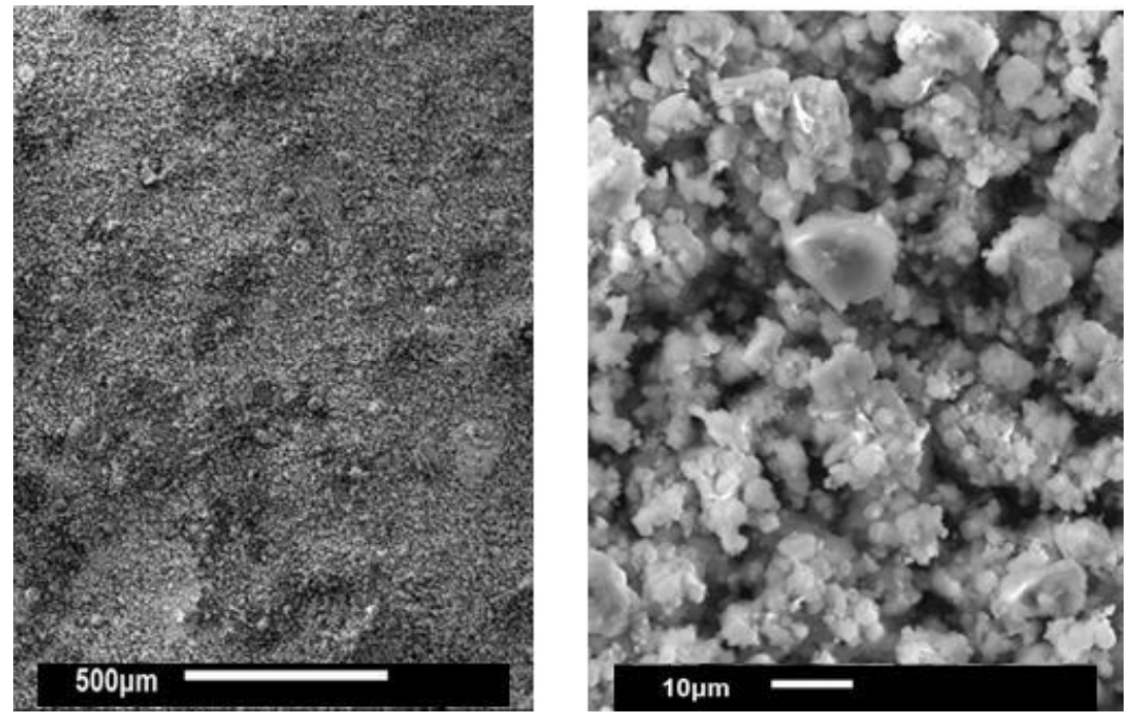

Figure 2: Surface observations at low (left) and high (right) magnification (SEM, SE mode). 

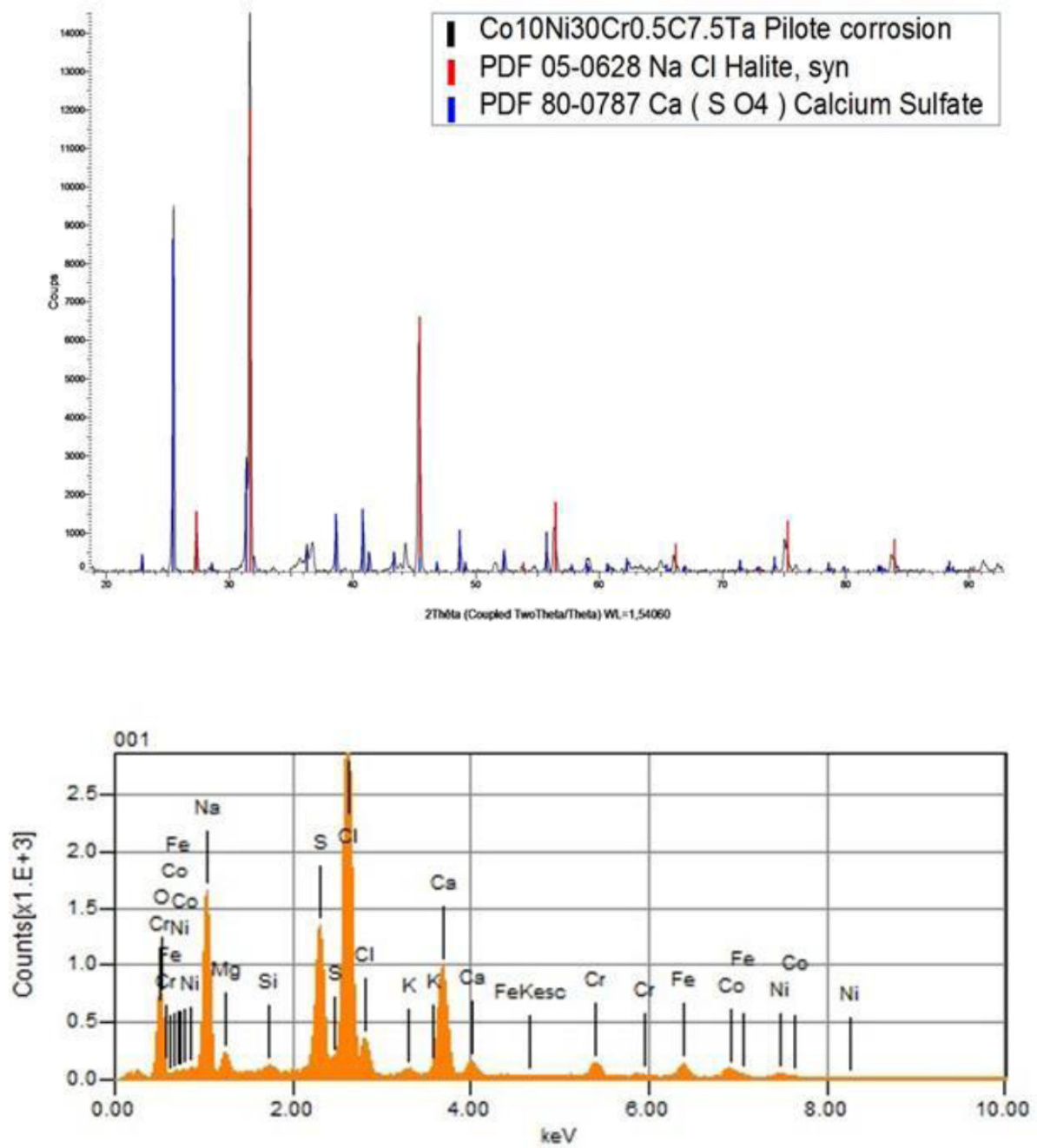

Figure 3: X-ray diffractogram (top) and EDS spectrum (bottom) acquired on the corrosion products formed over the "TAC" sample after test.

and crystals coming from the scoria introduced upstream: $\mathrm{NaCl}$ and $\mathrm{Ca}\left(\mathrm{SO}_{4}\right)$ as identified by $\mathrm{XRD}$ and EDS (Figure 3).

SEM micrographs taken in BSE mode on the tested sample after its cross-sectional metallographic preparation, with again two magnifications, are displayed in Figure 4. The corrosion products as well as the subsurface degradation of the alloys can be observed. EDS spot analyses, carried out here and there in the layer of corrosion products, evidence the presence of a (Co, Ni)O oxide and of the $\mathrm{CoCr}_{2} \mathrm{O}_{4}$ spinel oxide, as well as inclusions, some of them made of $\mathrm{Ca}\left(\mathrm{SO}_{4}\right)$ (Figure 5).

The eutectic $\mathrm{TaC}$ carbides, present in the interdendritic spaces, seem to be unchanged, close to the oxidation front (no inwards development of a carbide-free zone) as well as in the bulk (they kept their script morphology, and did not become fragmented).
However, at high magnification, it appears that oxidation developed inwards. This consumed the alloy matrix and transformed the tantalum carbides in oxides having the same morphology as the initial carbides.

\section{DISCUSSION}

Despite the rather low temperature in this experiment the tested alloy was severely degraded by regards to how it is to behave when exposed to air at much higher temperatures, this demonstrating the aggressiveness of the $\mathrm{WtE}$ environment.

Concerning this "TAC" alloy the average thickness of the oxide scales formed is of the same order of magnitude as when this alloy is exposed at $1000^{\circ} \mathrm{C}$ during about fifty hours, as observed in an earlier study [11]. In contrast with oxidation at $1000^{\circ} \mathrm{C}$ in air the oxidation products are here very different. The external oxide scales obtained at $1000^{\circ} \mathrm{C}$ after 50 hours of 

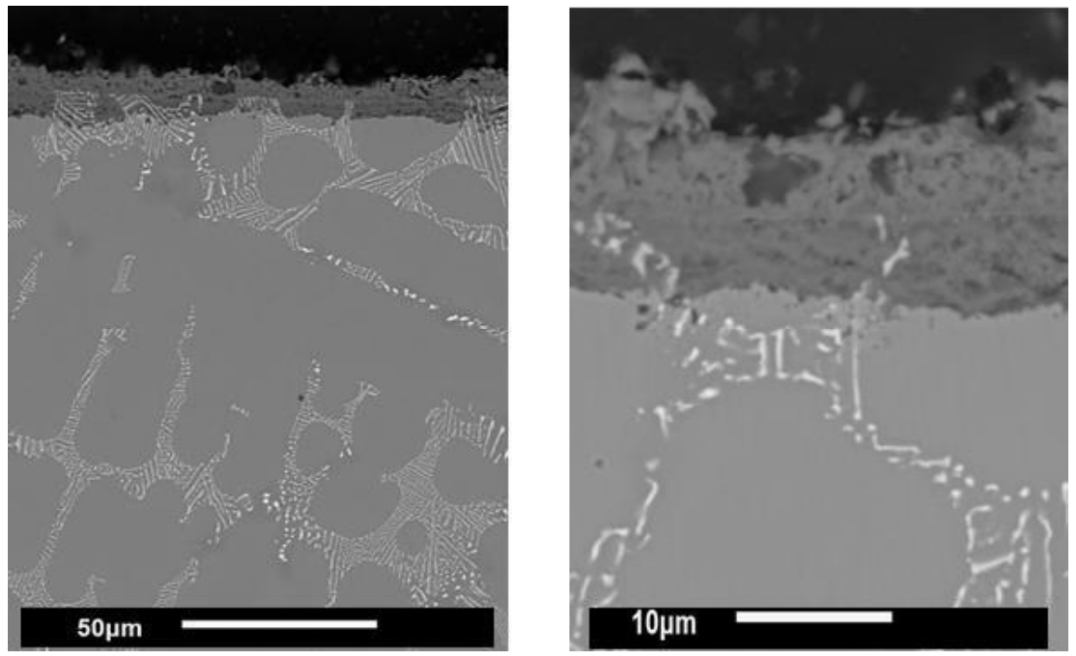

Figure 4: Surface observations at low (left) and high (right) magnification (SEM, SE mode).
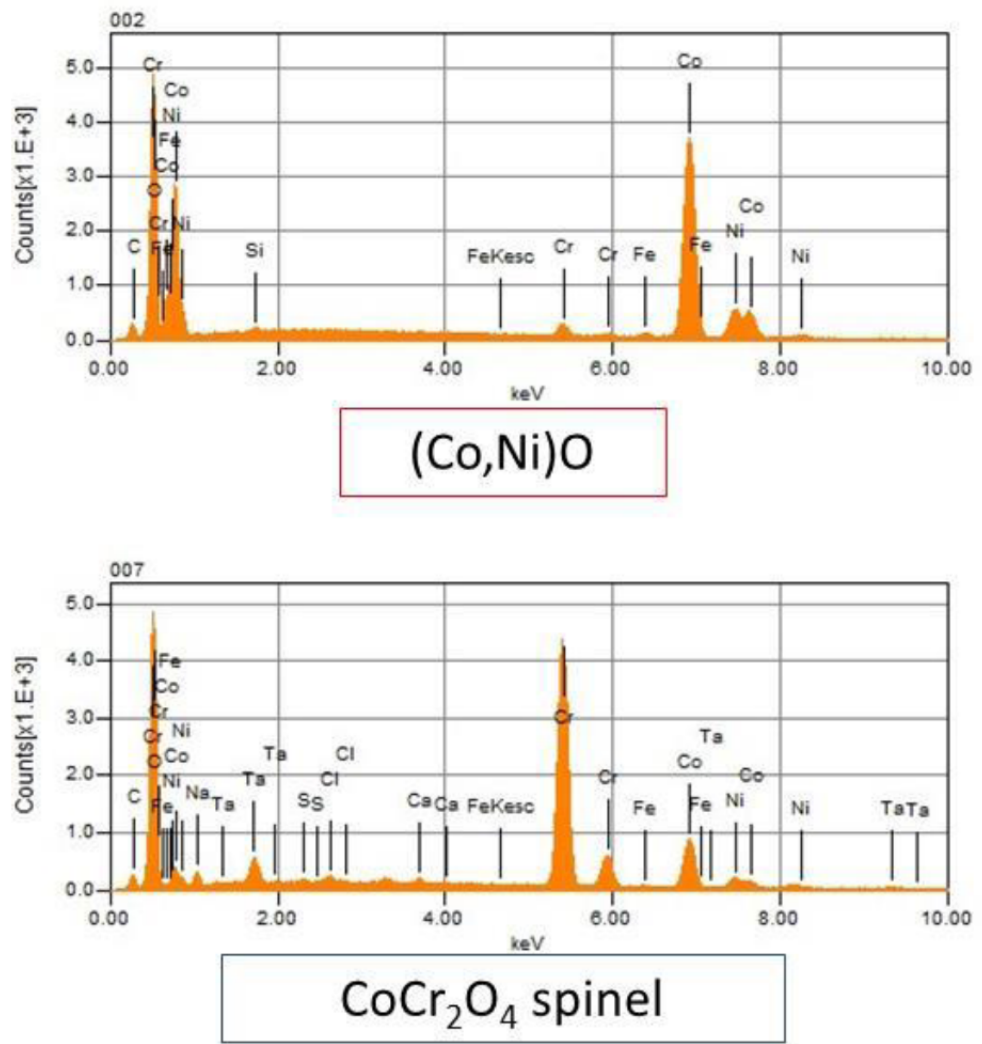

Figure 5: Identification of oxides present on surface and in subsurface of the "TAC" sample.

exposure to air was a continuous compact chromia scale developed outwards (Figure 6). In this chromia scale $\mathrm{CrTaO}_{4}$ was present here and there as films mixed with the chromia scale. This oxide was also present in the outer part of the subsurface. After oxidation at $1000^{\circ} \mathrm{C}$ again, a zone losing its $\mathrm{TaC}$ carbides initially present developed inwards from the alloy/external oxide scale interface. In the present case the external oxide is porous and must be considered as composed of two distinct layers. The outer one did not contain other oxides than (Co, $\mathrm{Ni}) \mathrm{O}$ and $\mathrm{CoCr}_{2} \mathrm{O}_{4}$ spinel while the inner layer also contains $\mathrm{CrTaO}_{4}$ oxides. Considering the distribution and morphology of these $\mathrm{CrTaO}_{4}$ oxides, these ones appear as resulting of the in situ oxidation of the TaC carbides initially present in the same location (interdendritic) with the same morphology (script-like). 


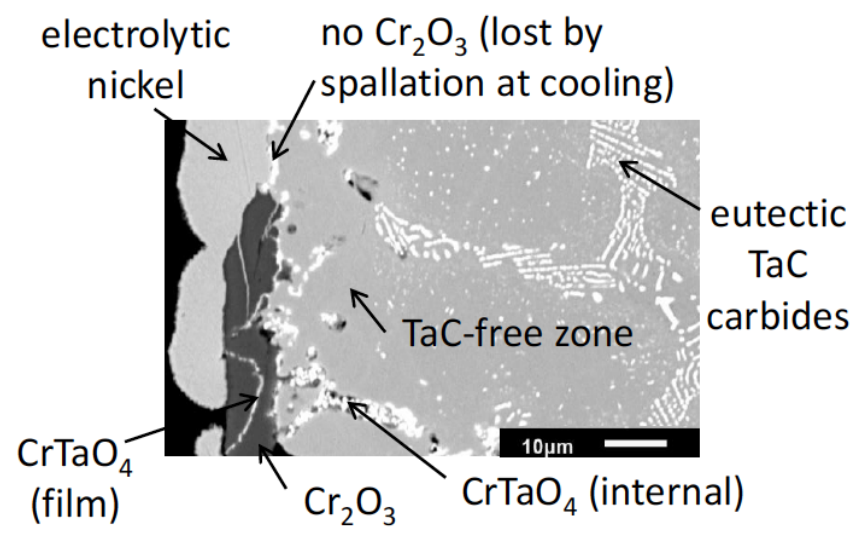

Figure 6: SEM/BSE micrograph of oxidized surface and subsurface of the "TAC" alloy oxidized at $1000^{\circ} \mathrm{C}$ after $46 \mathrm{~h}$ of exposure to synthetic air.

Probably due to the low temperature of the test, one can guess that the big Ta atoms were not able to diffuse toward the oxidation front as they do at $1000^{\circ} \mathrm{C}$ in such alloy (i. e. with formation of films of $\mathrm{CrTaO}_{4}$ or subsurface accumulation of $\mathrm{CrTaO}_{4}$ ) and they were oxidized where they were, by oxygen diffusing inwards. The part of oxide spinel oxide and cobalt oxide formed in the vicinity of these script-like tantalum oxide probably grew inwards by anionic diffusion while the outer part grew outward by cationic diffusion. In this hypothesis, by its in situ oxidation tantalum played the role of marker of the initial surface.

\section{CONCLUSIONS}

Despite it earlier proved its high chemical resistance in air at much higher temperature than in the present study this cobalt alloy was severely corroded in the complex atmosphere generated here to simulate the working conditions of WtE boilers. Only beginnings of possible explanations were formulated to interpret the different types of degradation affecting this alloy and thorough investigations stay to be carried out to understand much better what occurred to this alloy. But this one clearly appears to be able to correctly behave in such situation in its present state. Indeed this $\mathrm{TaC}$ containing alloy suffered fast degradation with both outward and inward growth of the external scales, these ones being furthermore clearly not protecting taking into account their natures (oxide of cobalt and spinel, no chromia) and their porosities states. In the second part of this work, this will be the case of the second cobalt alloy which will be examined [12], by characterization of its degradation in another context, exposed to the same complex gas stream and to model ashes in which it was immersed.

\section{ACKNOWLEDGMENTS}

This work was carried out by several members of the french Groupe de Recherche GDR CNRS 3583 "EVACOHT" (Effet de la Vapeur d'eau en Atmosphères complexes sur la Corrosion et l'Oxydation à Haute Température). The authors wish thanking the Centre National de la Recherche Scientifique (CNRS) for the favorable conditions brought to this work.

\section{REFERENCES}

[1] Kalsi SBS, Sidhu TS. Singh H. Proceedings of the Materials Science and Technology Conference \& Exhinition, Columbus (OH, USA, Oct. 16-20, 2011), 1125 (2011).

[2] Kong $Y$, Davidson $H$. Proceedings of the $18^{\text {th }}$ Annual North American Waste to Energy Conference (Orlando, FL, United States, May 11-23, 2010), 317 (2010)

[3] Kawahara Y. Handbook of Advanced Ceramics ( $2^{\text {nd }}$ edition), 807 (2013).

[4] Weidemann E, Allegrini E, Fruergaard Astrup T, Riber C, Jansson S. Waste management, 2016; 49: 110.

[5] Kawara Y. Materials at High Temperatures, 1997; 14(3): 261 https://doi.org/10.1080/09603409.1997.11689552

[6] Kawahara Y, Sasaki K, Nakagawa Y. Materials Science Forum (High Temperature Oxidation and Corrosion 2005), 2006; 513: 522-523.

[7] Y. Kawara; Material, 2001; 40(4): 346.

[8] Donachie MJ, Dionachie SJ. Superalloys: A Technical Guide ( $2^{\text {nd }}$ edition), ASM International, Materials Park (2002).

[9] Young DJ. High Temperature Oxidation and Corrosion of Metals, Elsevier, Amsterdam (2008).

[10] Berthod P, Bernard JL, Liébaut C. Patent, WO2001090429 A1 20011129.

[11] Aranda L, Schweitzer T, Berthod P, Navet A, Leroy A. Proceedings of Eurocorr 2014 (Pisa, Italy).

[12] Aranda L, Thierry Schweitzer, Patrice Berthod, Christophe Rapin, Didier Souchon, Farès Maad, Jean-Michel Brossard; Journal of Materials Science and Technology Research 2018; 5: 6-10. 